\title{
Ganglioneuroma in the Small Intestine of a Juvenile Pig
}

\author{
Mami MURAKAMI ${ }^{1)}$, Hiroki SAKAI ${ }^{1) *}$, Kenji MIZUTANI ${ }^{2)}$ and Tokuma YANAI ${ }^{1)}$ \\ ${ }^{1)}$ Laboratory of Veterinary Pathology, Department of Veterinary Medicine, Faculty of Applied Biological Sciences, Gifu University, 1-1 \\ Yanagido, Gifu 501-1193 and ${ }^{2}$ Gifu Prefectural Meat Inspection Office, 3-167-1 Hayashi-cho, Ohgaki 503-0015, Japan
}

(Received 19 May 2011/Accepted 15 June 2011/Published online in J-STAGE 29 June 2011)

ABSTRACT. A mass was located in the small intestine of a slaughtered 6-month-old male Landrace-cross pig that had no clinical abnormalities. This egg-shaped well-circumscribed mass was situated in the submucosal and muscular tissue layers and protruded into the lumen. Histopathologically, the tumor comprised discrete or aggregated ganglion and schwannian cells in neuropil-like tissue. Some ganglion cells contained Nissl substance in their cytoplasm. The ganglion cells stained positive for neuron-specific enolase, class III $\beta$ tubulin, neurofilament, and synaptophysin; the schwannian cells stained positive for vimentin, S-100 protein, and glial fibrillary acidic protein. The tumor was diagnosed as a ganglioneuroma in accordance with these findings. Here, we have reported detailed immunohistochemical findings in addition to the histopathological features of a swine ganglioneuroma. KEY WORDS: ganglioneuroma, immunohistochemistry, small intestine, swine.

Ganglioneuromas have been reported to occur in humans and in domestic and non-domestic animals [1, 3, 5-8, 11, $13,16]$. In human, ganglioneuromas tend to occur in children and adolescents and are commonly located in the thorax or abdomen [3, 11]. In dogs, ganglioneuromas most commonly tend to occur in the central nervous system, followed by the alimentary tract, and the peripheral nervous system; in other animals such as cats, horses, and pigs, the alimentary tract is the most common site $[1,5,6,12,15]$. In this study, in addition to the histopathological features, we have reported immunohistochemical findings, including those for neuronal cell-specific antibodies, of an intestinal ganglioneuroma in a juvenile pig.

A tumor was detected in the small intestine of a slaughtered 6-month-old male Landrace-cross pig during meat inspection. The pig showed no significant abnormalities on antemortem examination. The egg-shaped well-circumscribed tumor (maximum diameter, approximately $8 \mathrm{~cm}$ ) protruded into the lumen causing stricture, but not obstruction. The tumor had a firm solid cut surface, which was milky white and tan (Fig. 1a). The overlying mucosa was intact.

The tumor tissue was fixed in $10 \%$ buffered neutral formalin, embedded in paraffin, processed routinely, sectioned, and stained with hematoxylin and eosin (HE) and cresyl violet solution. Immunohistochemical analysis was performed for the additional tissue sections by using the polymer immunocomplex method (Envision+; Dako, Glostrup, Denmark). Details regarding the immunohistochemical studies and antibodies are shown in Table 1 . The sections with primary antibodies were incubated overnight at $4{ }^{\circ} \mathrm{C}$. For visualization, the sections were developed in a $3,3^{\prime}$ -

\footnotetext{
* Correspondence to: SAKai, H.,Laboratory of Veterinary Pathology, Department of Veterinary Medicine, Faculty of Applied Biological Sciences, Gifu University, 1-1 Yanagido, Gifu 5011193, Japan.

e-mail: shiroki@gifu-u.ac.jp
}

diaminobenzidine solution (Liquid DAB+ Substrate-Chromogen System; Dako) and then counterstained with Mayer's hematoxylin.

Histopathologically, the lesion comprised a neural tissue, resembling the neuropil, in the submucosal and muscle layers. Varying numbers of ganglion and schwannian cells were embedded in this tissue (Fig. 1b). The ganglion cells varied in size and had a stellate-to-polygonal clear-to-eosinophilic cytoplasm and a large vesicular round nucleus with a prominent nucleolus. The tumor cells showed variable degrees of differentiation, and the large mature ganglion cells had distinct cresyl violet-positive Nissl substance in the cytoplasm. Mature ganglion cells were sparse in neuropil-like-rich areas (Fig. 1c), and the occasional mature ganglion cell was accompanied by small spindle-shaped condensed cells, which were termed satellite cells. In contrast, immature or maturing ganglion cells were found to be aggregated in areas where the neuropil-like tissue was sparse (Fig. 1d). The schwannian cells had pale scant cytoplasm and a condensed ellipsoid- to spindle-shaped nucleus. Some schwannian cells occurred in small clusters, but the majority were scattered throughout the neuropil-like tissue. Mitotic figures were rarely observed in the schwannian cell component. The muscle layers were disrupted by abundant large bundles of neoplastic neural tissue; however, minimal neoplastic invasion of the lamina propria was observed.

Immunohistochemical analysis showed that the ganglion cells stained positive for neuron-specific enolase (NSE; Fig. 1e), class III $\beta$-tubulin (Fig. 1f), and synaptophysin and that some ganglion cells and neurites showed intense positive staining for neurofilament. The schwannian cells stained positive for vimentin, S-100 protein, and glial fibrillary acidic protein (GFAP; Fig. 1g). Positive staining for Ki-67 antigen was observed in some schwannian cells but only occasionally in immature ganglion cells.

Neuroblastic neoplasms include neuroblastomas, ganglioneuroblastomas, and ganglioneuromas and are classified 

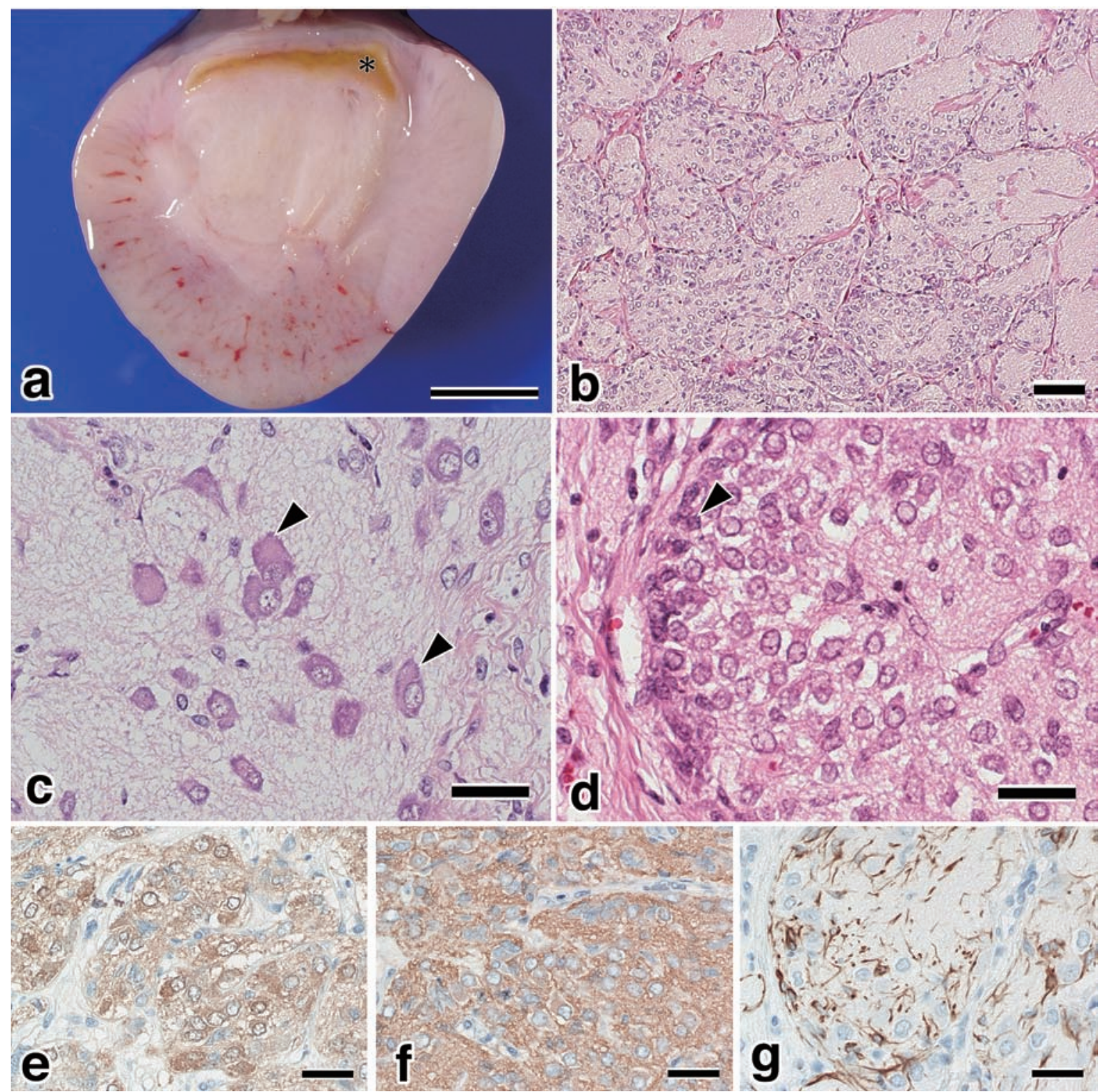

Fig. 1. Macroscopic and microscopic examinations of the pathological and immunohistochemical findings of a small intestinal ganglioneuroma in a pig. (a) Cut surface of the tumor. The asterisk $\left(^{*}\right)$ indicates the intestinal lumen. The cut surface is solid, milky white and tan, and has a firm texture. The intestinal lumen is strictured by the protruding tumor but is not obstructed, and the overlying mucosa is intact. Bar $=1.5 \mathrm{~cm}$. (b) Low magnification of the tumor. The lesion comprised a neural tissue, resembling the neuropil. Varying numbers of ganglion and schwannian cells were embedded in this tissue. Hematoxylin and eosin staining (HE). Bar $=100 \mu \mathrm{m}$. (c) High magnification of the neuropil-rich area. Mature and maturing ganglion cells (arrowheads) are embedded in the neuropil-like tissue. HE. Bar $=30 \mu \mathrm{m}$. (d) High magnification of the high-cellularity area. Immature ganglion cells are clustered in the scant neuropil-like tissue. The schwannian cells have a pale scant cytoplasm and a condensed ellipsoid- to spindle-shaped nucleus, and some schwannian cells are found to be aggregated (arrowhead). HE. Bar $=30 \mu \mathrm{m}$. (e) The ganglion cells in the high-cellularity area show strong cytoplasmic and nuclear positive staining for neuron-specific enolase. Immunohistochemistry. Bar $=30$ $\mu \mathrm{m}$. (f) The cytoplasm of the tumor cells and neuropil-like tissue stains positive for class III $\beta$-tubulin. Immunohistochemistry. Bar $=30 \mu \mathrm{m}$. (g) The cytoplasm of schwannian cells shows positive immunoreactivity for glial fibrillary acidic protein. Immunohistochemistry. Bar $=30 \mu \mathrm{m}$.

on the basis of the degree of differentiation of neoplastic neuroblasts and the quantity of schwannian stroma $[9,14]$. Neuroblastomas comprise neuroblastic cells and delicate fibrovascular septa with some degree of schwannian prolif- eration. Ganglioneuroblastomas are characterized by immature neuroblasts and large mature ganglion cells in schwannian stroma. Ganglioneuromas comprise proliferating schwannian cells, which stain positive for S-100 and 
Table 1. Antibodies used for immunohistochemical staining

\begin{tabular}{lcccc}
\hline Antigen & Clone & Dilution & Pretreatment & Manufacturer $^{\mathrm{d})}$ \\
\hline Cytokeratin & AE1/AE3 & Prediluted & HIAR $^{\mathrm{c}}$ & Dako \\
Vimentin & V9 & Prediluted & HIAR & Dako \\
S-100 & Polyclonal & Prediluted & HIAR & Dako \\
GFAP $^{\text {a) }}$ & Polyclonal & $1: 400$ & HIAR & Dako \\
NSE $^{\text {b }}$ & Polyclonal & $1: 10,000$ & HIAR & Millipore \\
Neurofilament & 2F11 & $1: 25$ & HIAR & Dako \\
Class III $\beta$-tubulin & 5G8 & $1: 10,000$ & HIAR & Promega \\
Synaptophysin & SY38 & $1: 50$ & HIAR & Dako \\
Ki-67 antigen & MIB-1 & $1: 50$ & HIAR & Dako \\
\hline
\end{tabular}

a) GFAP, glial fibrillary acidic protein; b) NSE, neuron-specific enolase; c) HIAR, heat-induced antigen retrieval treatment using Target Retrieval Solution, pH 6.0 (DakoCytomation) ;d) Dako, DakoCytomation, Glostrup, Denmark; Millipore, Billerica, MA, U.S.A.; Promega, Madison, WI, U.S.A.

GFAP; connective tissue; and discrete or aggregated ganglion cells, which stain positive for neurofilament, NSE, and class III $\beta$-tubulin $[10,13]$. In the present case, although the degree of maturation of the ganglion cells varied, neuroblasts were not observed; therefore, the histopathological features were consistent with those for ganglioneuroma. Furthermore, differential diagnosis was required in this case between ganglioneuroma and ganglioneuromatosis. Ganglioneuromatosis is a rare lesion that comprises segmental diffuse proliferation of nerve fibers, ganglion cells, and the supporting cells of the enteric nervous system; these proliferative components are similar to those of ganglioneuromas. Ganglioneuromas and ganglioneuromatosis have not been well documented in the case of animals, even in the WHO classification, and distinguishing between them on the basis of the proliferating cells is difficult; however, the growth pattern is important for differentiating between a ganglioneuroma and ganglioneuromatosis $[5,6]$. Ganglioneuromatosis involves the mucosa and/or the mesenteric plexuses, commonly shows transmural infiltration [2, 4-6], is diffuse and poorly demarcated, and affects an entire bowel segment $[2,4]$. Therefore, a typical characteristic of ganglioneuromatosis is that the affected bowel segment is thickened and the lumen is dilated $[2,4]$. In contrast, a ganglioneuroma occurs as an intraluminal mass $[5,6]$. In the present study, the gross lesion was a mass in the intestinal wall rather than a diffuse growth in the intestinal segment. Therefore, in this case, the lesion satisfied the criteria for ganglioneuroma, i.e., ganglioneuromatous components without involvement of all 3 layers of the bowel wall.

To our knowledge, only 1 case of multiple intestinal ganglioneuromas in swine has been previously reported; this tumor was also found during meat inspection, with no signs of metastasis. No symptoms had been observed in the pig before it was slaughtered [15]. On the basis of the lesion location in the reported case, the tumor origin was considered to be the submucosal and/or myenteric plexus of the jejunum [15]. In our case, although the origin of the ganglioneuroma was uncertain, this tumor also probably originated from the submucosal or myenteric plexus because the lesion was mainly located in the submucosal and myenteric plexus.

\section{REFERENCES}

1. Allen, D., Swayne, D. and Belknap, J. K. 1989. Ganglioneuroma as a cause of small intestinal obstruction in the horse: a case report. Cornell Vet. 79: 133-141.

2. D'amore, E. S. G., Manivel, J. C., Pettinato, G., Niehans, G. A. and Snover, D. C. 1991. Intestinal ganglioneuromatosis: mucosal and transmural types. A clinicopathologic and immunohistochemical study of six cases. Hum. Pathol. 22: 276-286.

3. De Bernardi, B., Gambini, C., Haupt, R., Granata, C., Rizzo, A., Conte, M., Tonini, G. P., Bianchi, M., Giuliano, M., Luksch, R., Prete, A., Viscardi, E., Garaventa, A., Sementa, A. R., Bruzzi, P. and Angelini, P. 2008. Retrospective study of childhood ganglioneuroma. J. Clin. Oncol. 26: 1710-1716.

4. Hazell, K. L. A., Reeves, M. P. and Swift, I. M. 2011. Small intestinal ganglioneuromatosis in a dog. Aust. Vet. J. 89: 1518.

5. Head, K. W., Else, R. W. and Dubielzig, R. R. 2002. Tumors of the alimentary tract. pp. 401-482. In: Tumors in Domestic Animals, 4th ed. (Meuten, D. J. ed.), Iowa State University Press, Ames, Iowa.

6. Head, K. W., Cullen, J. M., Dubielzig, R. R., Else, R. W., Misdorp, W., Patnaik, A. K., Tateyama, S. and van der Gaag, I. 2003. Histological Classification of Tumors of the Alimentary System of Domestic Animals, Armed Forces Institute of Pathology, Washington, D. C.

7. Koestner, A. and Higgins, R. J. 2002. Tumors of the nervous system. pp. 697-738. In: Tumors in Domestic Animals. 4th ed. (Meuten, D. J. ed.), Iowa State University Press, Ames, Iowa.

8. Koestner, A., Bilzer, T., Schulman, F. Y., Summeres, B. A. and Winkle, T. J. V. 1999. Histological Classification of Tumors of the Nervous System of Domestic Animals, Armed Forces Institute of Pathology, Washington, D. C.

9. Lonergan, G. J., Schwab, C. M., Suarez, E. S. and Carlson, C. L. 2002. Neuroblastoma, ganglioneuroblastoma, and ganglioneuroma: radiologic-pathologic correlation. Radiographics 22: 911-934.

10. Nyska, A., Shamir, M. H., Harmelin, A., Sandbank, J. and Waner, T. 1995. Intracranial gangliocytoma in a dog. Vet. Pathol. 32: 190-192.

11. Papavramidis, T. S., Michalopoulos, N., Georgia, K., 
Kesisoglou, I., Valentini, T., Georgia, R. and Papavramidis, S. T. 2009. Retroperitoneal ganglioneuroma in an adult patient: a case report and literature review of the last decade. South. Med. J. 102: 1065-1067.

12. Patnaik, A. K., Lieberman, P. H. and Johnson, G. F. 1978. Intestinal ganglioneuroma in a kitten - a case report and review of literature. J. Small Anim. Pract. 19: 735-742.

13. Sakai, H., Yonemaru, K., Takeda, M., Niimi, K., Murakami, M., Hirata, A. and Yanai, T. 2011. Ganglioneuroma in the urinary bladder of a dog. J. Vet. Med. Sci. 73: 801-803.

14. Shimada, H., Ambros, I. M., Dehner, L. P., Hata, J., Joshi, V. V. and Roald, B. 1999. Terminology and morphologic criteria of neuroblastic tumors: recommendations by the International Neuroblastoma Pathology Committee. Cancer 86: 349-363.

15. Une, Y., Iwama, K., Yoshida, H., Shirota, K., Nomura, Y. and Saito, Y. 1984. Multiple ganglioneuroma derived from intramural plexus of jejunum in a sow. Nippon Juigaku Zasshi 46: 247-250.

16. Yasui, Y., Ohta, Y., Ueda, Y., Hasegawa, K., Kihara, T., Hosoi, M., Miyajima, R., Shiga, A., Imai, K. and Toyoda, K. 2009. Spontaneous ganglioneuroma possibly originating from the trigeminal ganglion in a $\mathrm{B} 6 \mathrm{C} 3 \mathrm{~F} 1$ mouse. Toxicol. Pathol. 37: $343-347$. 